Res Publica. Revista de Historia de las Ideas Políticas

ISSN: $1576-4184$

http://dx.doi.org/10.5209/RPUB.59698

\title{
Poder, violencia y revolución en Walter Benjamin y Hannah Arendt
}

\author{
María Mercedes Miralpeix*; Carlos Ortega Insaurralde**
}

Recibido: 14 de mayo de 2017 / Aceptado: 11 de diciembre de 2017

Resumen. En este trabajo nos abocaremos al análisis de los conceptos de poder, violencia y revolución en las reflexiones de Walter Benjamin y Hannah Arendt. Dichos conceptos resultan claves para comprender las dificultades presentes en ambos autores a la hora de pensar la problemática de la aparición de nuevos agentes políticos en el espacio público-político. A partir de este problema, nos interesa explorar la posible complementariedad de los análisis de Hannah Arendt y de Walter Benjamin en relación a estas problemáticas. Así, argumentaremos que, más allá de las diferencias de los planteos de Benjamin y de Arendt en el análisis que hacen sobre la violencia, el poder y la revolución, ambos coinciden en que en esta última la aparición de nuevos actores políticos (Arendt), como así también la irrupción de experiencias políticas del pasado que han quedado ocultas (Benjamin), redefinen el rol de la violencia y el poder en el espacio político.

Palabras clave: Poder; violencia; revolución; Walter Benjamin; Hannah Arendt.

\section{[en] Power, Violence and Revolution in Walter Benjamin and Hannah Arendt}

\begin{abstract}
In this paper we'll analyze the concepts of power, violence and revolution in the reflections of Walter Benjamin and Hannah Arendt. These concepts are key for understanding the difficulties present in both authors when thinking on the problem of the emergence of new political agents in the publicpolitic space. In this context, what interests us is to explore a possible complementarity of the analyses of both Arendt and Benjamin with respect to this specific problematic, a complementarity that could, from our point of view, help to overcome those difficulties. In this sense, we will argue that, beyond the differences in the approaches of both authors with relation to the analysis of violence, power and revolution, they concur in the idea that, in a revolution, the creation of new political actors (Arendt) and the irruption of past political experiences (Benjamin) redefines the role of violence and power in the public-political space.
\end{abstract}

Keywords: Power; violence; revolution; Walter Benjamin; Hannah Arendt.

Sumario: 1. Introducción. 2. La crítica de la violencia de Walter Benjamin. 3. Arendt y el problema de las revoluciones modernas. 4. Una complementariedad posible entre Benjamin y Arendt. 5. Consideraciones finales sobre el poder, la violencia y la revolución

Cómo citar: Miralpeix, M. M.; Ortega Insaurralde, C. (2018). Poder, violencia y revolución en Walter Benjamin y Hannah Arendt, en Res publica 21.1, 77-89.

\footnotetext{
* Consejo Nacional de Investigaciones Científicas y Técnicas (Argentina) mercedesmiralpeix@gmail.com

** Universidad Nacional de Salta (Argentina) charlyoinsaurralde@gmail.com
} 


\section{Introducción}

En La condición humana ${ }^{1}$ Hannah Arendt sostiene que la violencia no debe ocupar un lugar en el espacio público-político, pues, dado que se encuentra sujeta a la necesidad, pertenece al ámbito de la esfera privada. Sin embargo, cinco años más tarde, en Sobre la revolución ${ }^{2}$, le otorgará un tratamiento diferente, aproximándose a una justificación de su uso político. Con todo, si bien existe un tratamiento político de la violencia en esta obra, sostenemos que para Arendt ésta sigue siendo esencialmente pre-política, de manera que el interés por las revoluciones modernas no se encuentra dado por el uso de la violencia con fines políticos sino por el "poder de reunión"3, el cual permite la fundación de nuevos espacios de libertad, es decir, de espacios que permitan la acción y el discurso, sostenidos por instituciones acordes a tal fin. Sin embargo, el planteo de Arendt acerca de la revolución encuentra un límite: al representarse la política como un fin en sí mismo, esto es, como el espacio en donde los hombres libres actúan entre iguales, excluye de su tratamiento el problema de las diferencias de poder social entre grupos, reduciendo lo que ella denomina "cuestión social" al problema de la pobreza.

Benjamin, por su parte, afirma en Para una crítica de la violencia ${ }^{4}$ que el análisis de la violencia debe hacerse relacionándola necesariamente con los conceptos de derecho y de justicia. Lo que distingue a la violencia desde el punto de vista del derecho (sea éste el positivo o el natural) es su carácter instrumental, esto es, que es que siempre un medio para un fin. En este contexto, Benjamin distingue dos formas de violencia íntimamente conectadas: la violencia fundadora de derecho y la violencia conservadora de derecho. Ambas constituyen un ciclo fatídico del que no se puede salir y que se encarna de manera más acabada en las policías de los estados modernos. Estas dos formas de violencia, que Benjamin denomina como "violencia mítica", se oponen diametralmente a otro tipo de violencia, a la que llama divina. Esta última sería la violencia propiamente revolucionaria, pues rompería con el ciclo mítico de violencia fundadora de derecho y violencia conservadora de derecho y, a la vez, con la lógica instrumental de la violencia mítica, siendo por esto un "puro medio". En este texto, Benjamin considera que la "huelga general revolucionaria" teorizada por Georges Sorel $l^{5}$ sería una forma concreta en la que se encarnaría la violencia divina. No obstante, Benjamin parece pensar la revolución en términos puramente negativos, es decir, más como destrucción que como creación de un nuevo orden social, económico y político. Esto nos parece problemático pues no permite pensar cómo sería posible sostener en el tiempo y en el espacio una sociedad liberada de la "violencia mítica".

Si bien a simple vista estos análisis sobre la violencia, el poder y la revolución parecen antitéticos ${ }^{6}$, nos interesa mostrar de qué manera es posible complementar

\footnotetext{
H. Arendt, La condición humana, Buenos Aires, Paidós, 2015 [1958].

H. Arendt, Sobre la revolución, Madrid, Alianza, 2008 [1963].

Cf. A. Di Pego, La modernidad en cuestión. Totalitarismo y sociedad de masas en Hannah Arendt, La Plata, Edlup, 2015.

4 W. Benjamin, "Para una crítica de la violencia", en Obras II/1, Madrid, Abada, 2007, pp. 183-206.

5 Para una discusión sobre el carácter problemático de esta apropiación, véase C. Pérez López, "Walter Benjamin y Georges Sorel: Entre el mito de la huelga general y una política de medios puros", en Trans/Form/Ação 38/1, 2015, pp. 213-238.

6 Para otros intentos de maridar las reflexiones de Benjamin y de Arendt sobre la violencia, el poder y la revolución, véanse: C. Finlay, "Hannah Arendt's Critique of Violence", en Thesis Eleven 97, 2009, p. 26-45; P. Birmingham, "On Violence, Politics, and the Law", en The Journal of Especulative Philosophy 24/1, 2010, pp.
} 
ambas visiones para pensar el problema de la aparición de nuevos actores políticos en el espacio público-político. Por un lado, consideramos que el intento de Benjamin por pensar una violencia que rompa con el ciclo mítico del derecho se puede enriquecer con la idea de "generaciones de vencidos" desarrollada en las tesis Sobre el Concepto de Historia ${ }^{7}$. Creemos que esta idea permitiría superar las limitaciones del planteo arendtiano sobre la "cuestión social". Por otro lado, pensamos que la idea de fundación de un orden institucional, que se mantiene en una constante tensión entre lo establecido y la novedad, es fundamental para otorgar una cierta estabilidad al espacio de libertad creado por la revolución sin negar la posibilidad de nuevos estallidos revolucionarios y, en este sentido, de la aparición de nuevas fundaciones y actores políticos. Aquí podemos encontrar una manera de pensar la revolución en términos positivos y no sólo de forma negativa como en Benjamin. Esta complementación es posible porque, en el fondo, el problema de ambos es el de la creación de espacios de libertad en los cuales la vida humana ya no esté sujeta inexorablemente al destino, en el caso de Benjamin, o a la necesidad, en el caso de Arendt.

\section{La crítica de la violencia de Walter Benjamin}

En su ensayo titulado Para una Crítica de la Violencia, publicado en 1921, Walter Benjamin parte de una exposición relacional de la violencia, vinculándola al derecho y a la justicia, pues "una causa operante de uno u otro modo se convierte en violencia (en el sentido enfático de la palabra) en cuanto se adentra en situaciones morales", es decir, cuando opera en un contexto normativo. En otras palabras, para Benjamin, "una acción puede asumir el status de violenta en el sentido estricto solo una vez que se encuentra en una relación moral"". Esto es así porque Benjamin considera que la problemática de la violencia es inherente a todas las cuestiones legales y morales, debido fundamentalmente a que el concepto en alemán moderno, Gewalt, posee una ambigüedad intrínseca: "refiere, a la vez, a la negación de la ley o de la justicia y a su realización o a la asunción de la responsabilidad por ellas por una institución (generalmente el estado)"10. En esta ambigüedad está escondido el carácter violento de la ley, aquella violencia que funda el estado y lo preserva, esto es, este posee una naturaleza dual, pues es, a la vez, un estado constitucional (cuando reina la norma) y un estado represivo (cuando reina la excepción) ${ }^{11}$. Aquí se encontraría lo "putrefacto en el derecho" 12 . En efecto, la violencia inherente en el derecho se contradice a sí

\footnotetext{
1-20; L. Lauwaert, “A Small Metaphysics of Violence. A Discussion Between Arendt, Benjamin, and Sorel?”, Tijdschrift voor Filosofie 77, 2015, pp. 785-813. De conjunto, estas intervenciones ponen en cuestión la lectura, dominante en la literatura secundaria, según la cual habría una marcada diferencia entre Benjamin y Arendt con respecto al problema de la relación entre la violencia, el poder y la revolución, determinada esencialmente por el tratamiento diferencial que realizan ambos autores de la propuesta filosófico-política de Georges Sorel. En tal dirección, nuestro trabajo puede ser leído como una contribución, con ribetes particulares, a la puesta en cuestión de esa interpretación dominante.

7 W. Benjamin, "Sobre el concepto de historia", en Obras I/2, Madrid, Abada, 2008, pp. 303-318.

$8 \quad$ W. Benjamin, "Para una crítica de la violencia", op. cit., p. 183.

9 S. Khatib, "Towards a Politics of Pure «Means»: Walter Benjamin and the Question of Violence", recuperado de http://anthropologicalmaterialism.hypotheses.org/1040, 2016, Nov. 11, aquí párr. 3.

10 É. Balibar, "Reflections on Gewalt", en Historical Materialism 17, 2009, pp. 99-125, aquí p. 101.

11 M. Tomba, "Another Kind of Gewalt. Beyond Law. Re-reading Walter Benjamin”, en Historical Materialism 17, 2009, pp. 126-144, aquí p. 135.

12 W. Benjamin, "Para una crítica de la violencia", op. cit., p. 198.
} 
misma porque la fuerza que hace que la ley se cumpla (la policía, por ejemplo) siempre disuelve la distinción entre la violencia conservadora de derecho y la violencia fundadora de derecho. Y viceversa, todos los intentos de quebrar la ley y los poderes que la sostienen conducen al establecimiento de un nuevo derecho. En este contexto, la cuestión que preocupa a Benjamin es cómo concebir una esfera política revolucionaria fuera y más allá del derecho, una esfera de justicia y violencia no-legal, es decir, "la pregunta por otros tipos de violencia" [die Frage nach andern Arten der Gewalt $]^{13}$.

Benjamin continúa el ensayo señalando que el dogma básico de cualquier teoría de la violencia es el que afirma que "pueden alcanzarse fines justos mediante medios legítimos, y unos medios legítimos se pueden aplicar a fines justos" ${ }^{14}$. En este marco, el de la relación entre medios y fines, Benjamin identifica dos escuelas del derecho que legitiman la violencia de distinta manera: el derecho natural, por un lado, sostiene que lo que importan son los fines justos; mientras que el derecho positivo, por el otro, afirma que lo importante son los medios justos. De cualquier forma, ambas escuelas cometen el mismo error: circunscriben la problemática de la violencia a los nexos instrumentales entre medios y fines. Benjamin, por el contrario, niega cualquier crítica de la violencia basada en una teoría de fines o medios justos. Para él, es necesario establecer un criterio independiente tanto para los fines justos como para los medios justificados. Esto implica una consideración histórico filosófica del derecho, en la que lo que importa es el sentido, no la utilización, de la violencia.

Como señalábamos más arriba al referirnos a la naturaleza dual del estado, Benjamin distingue dos formas de violencia que se presuponen y niegan entre sí: la violencia fundadora de derecho y la violencia conservadora de derecho. Es decir, la violencia estatal que preserva el derecho [rechtserhaltende Gewalt] y la violencia que termina creando un nuevo derecho [rechtsetzende Gewalt]. Ambos tipos de violencias son solo medios, pues solamente como tales pueden ser justificados: "en tanto que medio, toda violencia es instauradora de derecho o mantenedora de derecho"15. Benjamin denomina a estas dos formas de violencia como "violencia mítica", pues su dialéctica intrínseca conduce a una lógica circular e inescapable: cualquier acto destructor del derecho resulta en una nueva creación [positing / Setzung] de este que nuevamente intenta preservarse violentamente. Esto es, en efecto, lo "putrefacto en el derecho" o, en términos de Massimiliano Tomba, "la filosofía de la historia de la Gewalt"16. Las dos formas de violencia, como también señalamos anteriormente, se encuentran en la praxis de la policía. En ella, la distinción entre la violencia que impone derecho y la que lo defiende es suprimida: "la violencia policial es instauradora de derecho, ya que su función característica no consiste en promulgar leyes, sino ya todo edicto que ella misma pueda publicar empleando el respaldo de la ley; y es violencia mantenedora de derecho porque se pone a disposiciones de tales fines"17. La praxis policial ilustra de manera clara que no existe una frontera estable entre la violencia y el derecho, excepción y norma, estado represivo y estado constitucional. Benjamin va más allá, afirmando que la forma política en la que esta degeneración

13 Ibidem, p. 199: "Como [...] la resolución de las tareas humanas [...] es irrealizable si se renuncia por completo a la violencia, se impone la pregunta por otros tipos de violencia que los que menciona la teoría del derecho".

Ibidem, p. 184.

Ibidem, p. 193.

M. Tomba, op. cit., p. 134.

W. Benjamin, "Para una crítica de la violencia", op. cit., p. 192. 
de la violencia es posible es en la democracia, pues allí la existencia de las policías constituye "la mayor degeneración posible del poder"18.

Pero los efectos de la violencia mítica van más allá de la esfera estatal o del derecho. Tal vez más importante aún es la relación que Benjamin establece al final del texto entre lo que llama la "mera vida", la culpa y la violencia mítica. La "mera vida" es la vida biológica despojada de cualquier elemento humano, esencialmente la libertad. Esta vida es, según Benjamin, a la que se hace referencia cuando se sostiene la sacralización de la vida, y esta forma de pensar no sería otra cosa que mítica: "habría que pensar que lo que aquí se da como sagrado es, de acuerdo al pensamiento mítico, el portador de la inculpación, esto es, la mera vida" ${ }^{19}$. Es a partir de las fuerzas míticas, entendidas aquí, de manera amplia, como las que cercenan la libertad a través del mecanismo de la culpa, que surgen la violencia estatal, justificada por el derecho y la mera vida.

En contraposición a la violencia mítica, Benjamin propone pensar, teniendo en cuenta que su objetivo es, como dijimos, la superación de la naturaleza dual del estado y la "pregunta por otros tipos de violencia", en una forma de violencia que denomina como "violencia divina". Esta forma de violencia se caracteriza, en una primera instancia, por romper el nexo instrumental de medios y fines. Pero, más aún, la violencia divina corresponde a la desactivación revolucionaria de la violencia mítica, esto es, al "des-hacer del derecho a través de la deposición [Entsetzung] del ciclo de la violencia creadora de derecho y fundadora de derecho" ${ }^{20}$. Es, en otras palabras, la desactivación revolucionaria como violencia pura in-mediata que depone el derecho:

Al igual que dios se contrapone en la totalidad de los ámbitos al mito, la violencia divina se contrapone a la violencia mítica. En concreto, sin duda, la violencia divina es lo contrario a la violencia mítica en todos los aspectos. Si la violencia mítica instaura derecho, la violencia divina lo aniquila; si aquella pone límites, ésta destruye ilimitadamente; si la violencia mítica inculpa y expía al mismo tiempo, la divina redime; si aquella amenaza, ésta golpea; si aquella es letal de manera sangrienta, ésta vine a serlo de manera incruenta ${ }^{21}$.

Para darle un contenido concreto a esta idea de violencia revolucionaria como puro medio, Benjamin recurre a la distinción establecida por Sorel, en su Reflexiones sobre la violencia ${ }^{22}$, entre la huelga general política y la huelga general revolucionaria o proletaria. Esta última, en palabras de Benjamin:

No se da con la intención de reanudar el trabajo nuevamente tras obtener concesiones exteriores junto a concreta modificaciones de las condiciones de trabajo, sino con la decisión de reanudar un trabajo completamente transformado; uno no forzado por el Estado (un cambio radical que este tipo de huelga no provoca, sino que solo consuma). De ahí también que la primera de dichas empresas [la huelga general política] sea instauradora de derecho, mientras que la segunda [la

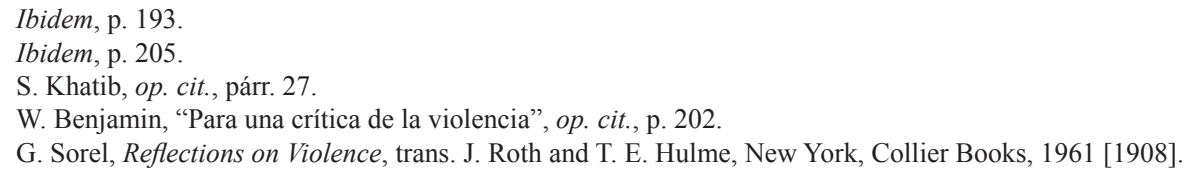


huelga general proletaria] es anarquista [...] A la hondura de esta concepción, moral y auténticamente revolucionaria, no es posible oponerle una consideración que tache de violencia a tal tipo de huelga general por sus posibles consecuencias catastróficas ${ }^{23}$.

Por lo tanto, la huelga general proletaria constituiría una violencia política noviolenta, pues consistiría fundamentalmente en la deposición del derecho y su violencia mítica. De este modo, este tipo de huelga rompería con el nexo instrumental de medios y fines. Es decir, sería un puro medio. Para Benjamin, esto la convierte en una huelga "anarquista", esto es, una acción puramente negativa, destructiva.

\section{Arendt y el problema de las revoluciones modernas}

Según Arendt en la época moderna el sentido de la política, entendida como ejercicio de la libertad a través de la acción y la palabra, habría sufrido un cambio sustancial producto de una sobrestimación de la capacidad de fabricación del hombre. Esto habría excluido a la acción, "la categoría política por excelencia"24 del ámbito político, al mismo tiempo que, la violencia, ínsita en todo proceso de fabricación, habría adquirido relevancia en el ámbito político del que, desde el mundo griego, estaba excluida.

Para los griegos, violencia y política constituían dos elementos opuestos: mientras que en el espacio privado la violencia podía ser justificada porque las relaciones que se establecían allí eran asimétricas, esto es, una relación de mando y obediencia, en el espacio público-político la violencia debía ser necesariamente excluida, porque el hombre que ingresaba a la polis interactuaba con pares a través de la acción y el discurso con el fin de persuadirlos y no de gobernarlos:

Ser político, vivir en una polis, significaba que todo se decía por medio de palabas y de persuasión, y no con la fuerza y la violencia. Para el modo de pensar griego, obligar a las personas por medio de la violencia, mandar en vez de persuadir, eran formas prepolíticas para tratar con la gente cuya existencia estaba al margen de la polis, del hogar y de la vida familiar, con ese tipo de gente en que el cabeza de familia gobernaba con poderes despóticos e indisputados ${ }^{25}$.

De este modo, isonomía e isegoría eran los conceptos que permitían pensar la experiencia política griega basada en la igualdad y la libertad. Se trataba, por un lado, de igualdad de palabra, esto es, que todos los miembros de la polis tenían el mismo derecho para hablar sobre los asuntos políticos y, por otro lado, de una igualdad ante la ley, que otorgaba el derecho a todos los hombres para actuar.

A partir de esto, las revoluciones modernas constituyen un foco problemático dentro del pensamiento arendtiano, ya que éstas suponen la apropiación de la violencia y la puesta en juego de la capacidad de fabricar, propia de todos los hombres, en aras de la construcción de nuevas sociedades y de nuevos espacios en donde inte-

\footnotetext{
W. Benjamin, "Para una crítica de la violencia", op. cit., p. 197.

H. Arendt, La condición humana, op. cit., p. 23.

Ibidem, p. 40.
} 
ractuar en libertad. Si el sentido de la política está dado, desde el mundo griego, por la capacidad de actuar del hombre, mediante el uso de la persuasión en los asuntos humanos, excluyendo, de este modo, a la violencia, resta preguntarnos si las revoluciones pueden ser consideradas acontecimientos políticos dado que en ellas prima el uso de la acción violenta y no de la persuasión. En lo que sigue, nos proponemos mostrar que el interés de Arendt por las revoluciones modernas no está dado por el uso de la violencia, inmanente a ellas, sino más bien, por el "poder de reunión" y por la fundación de nuevos espacios de libertad, lo que permitiría seguir caracterizando a la violencia como algo esencialmente pre-político y, de este modo, analizar a las revoluciones desde una perspectiva política.

Aunque violencia y poder suelen aparecer en manera conjunta en la esfera política y, sobretodo, en los estallidos revolucionarios modernos, Arendt los define como dos elementos opuestos. Mientras que la primera se encuentra vinculada al ámbito de los medios, el segundo se encuentra ligado al ámbito de la pluralidad. En este sentido, la violencia siempre debe ser justificada, debido a su carácter instrumental, mientras que el poder, por el contrario, no necesita justificación sino legitimación. En el alemán etimológicamente no habría un vínculo entre poder [Macht] y potencia, pero si lo habría entre esta última y violencia [Gewalt]. Esto es así porque Arendt define al poder como la capacidad de actuar en concierto, esto quiere decir que el poder "nunca es propiedad de un individuo; pertenece a un grupo y continúa existiendo sólo mientras el grupo se mantiene unido"26, mientras que la potencia "designa inequívocamente algo singular, una entidad individual; es una propiedad inherente a un objeto o una persona y pertenece a su carácter, que puede ponerse a prueba en relación con otras cosas o personas pero esencialmente independientes de ellas" ${ }^{27}$. En este sentido, la potencia guarda un vínculo con la violencia "dado que los instrumentos de la violencia, como todas las otras herramientas, se diseñan con el fin y el propósito de multiplicar la potencia natural hasta, en la última etapa de su desarrollo, poder sustituirla"28. Si bien en las revoluciones poder y violencia actúan de manera conjunta, éstos no pueden identificarse, ya que se aniquilarían, pues "allí donde uno rige absolutamente el otro está ausente" 29 . En este sentido, y a diferencia de lo que sostiene la tradición revolucionaria, Arendt afirma que es vano pensar en una justificación política de la violencia en relación a las revoluciones, debido a que serían posibles revoluciones no violentas ya que la importancia de éstas estriban en la capacidad que tienen los individuos para agruparse y actuar, es decir, por el poder y no por la violencia:

La violencia no promueve causas, ni historia ni revolución, ni progreso ni reacción; pero puede contribuir a dramatizar la querella y llamar la atención pública sobre ella [...] la violencia, contrariamente a lo que sostienen sus profetas, es antes un arma de reforma que de revolución ${ }^{30}$.

En Sobre la revolución, Arendt establece una distinción entre reforma y revolución y, al mismo tiempo, ofrece una nueva conceptualización en torno a la forma de

26 H. Arendt, Crisis de la república, Buenos Aires, El Cuenco de Plata, 2015, p. 147.

$27 \quad$ Ibidem, p. 148.

$28 \quad$ Ibidem, p. 150.

9 Ibidem, p. 159.

$30 \quad$ Ibidem, p. 181. 
concebir el poder, por lo que éste tendría un carácter polisémico. Por un lado, mientras que la reforma volvería a formar aquello que se habría deformado o corrompido, las revoluciones son irrupciones de lo totalmente nuevo, en este sentido, toda revolución funda un nuevo orden. Por otro lado, el carácter fundacional de la revolución se encuentra vinculado al poder y, más precisamente, a lo que Anabella Di Pego denomina "poder de reunión". En la Condición Humana, Arendt afirma que el poder

Solo es realidad donde palabra y acto no se han separado, donde las palabras no están vacías y los hechos no son brutales, donde las palabras no se emplean para velar intenciones sino para descubrir realidades, y los actos no se usan para violar y destruir sino para establecer relaciones y crear nuevas realidades ${ }^{31}$.

El poder de reunión, en cambio, surge cuando los hombres se agrupan e irrumpen en las calles con una serie de reclamos sin la necesidad de haber establecido un consenso previo, es decir, una forma del poder de reunión serían las manifestaciones espontáneas, donde se pone de manifiesto el poder de asociación de los individuos. Estas asociaciones "no son partidos, son organizaciones ad hoc que persiguen objetivos a corto plazo y desaparecen cuando el objetivo ha sido alcanzado" 32 . Sin embargo, estas dos formas de poder compartirían un núcleo común: suponen una reunión entre los hombres y no detentan un carácter instrumental. Ambas nociones de poder pueden pensarse como fenómenos que pueden aparecer junto a la violencia, pero en cualquier caso esta última es ejercida contra "otros" que se encuentran fuera de ese espacio de reunión, y no constituye una forma de interacción entre las personas de ese espacio. Es el poder de agruparse y no la violencia el que permitiría la irrupción de nuevos actores sociales en la escena política, en este sentido, el significado de la revolución para Arendt estaría dado por la presencia de dos elementos imprescindibles: la cuestión social, que es lo que permitiría la agrupación de los individuos y su irrupción en la escena política, y la fundación, que permitiría el establecimiento de un nuevo orden político.

Arendt define la cuestión social como el problema de la pobreza:

La pobreza es algo más que carencia; es un estado constante de indigencia y miseria extrema cuya ignominia consiste en su poder deshumanizante; la pobreza es abyecta debido a que coloca a los hombres bajo el imperio absoluto de sus cuerpos, esto es, bajo el estado absoluto de necesidad ${ }^{33}$.

El problema de la cuestión social adquirió relevancia política cuando los hombres cuestionaron que la pobreza era algo inherente a la condición humana, es decir, cuando pusieron en juicio la distinción entre pobres y ricos. Ahora bien, si en un principio la cuestión social juega un papel fuertemente revolucionario éste debe ser abandonado al momento de la fundación de un nuevo orden político que asegure estabilidad al nuevo espacio de libertad y, al mismo tiempo, que permita la irrupción de nuevas fundaciones en pos de aquel. De no ser así, la política misma se corrompería, pues ésta, en el pensamiento arendtiano, trata sobre el ejercicio de la libertad y, por ende,

\footnotetext{
H. Arendt, La condición humana, op. cit., p. 223.

H. Arendt, Crisis de la república, op. cit., p. 101.

H. Arendt, Sobre la revolución, op. cit., p. 79.
} 
los sujetos políticos deben estar librados de toda forma de necesidad. En este punto el planteo de Arendt se encuentra inmerso en un problema ya que supone una autonomía de la política, esto es, que no se encuentre sujeta a los problemas de clases, sino que éstos deberían ser superados para volver a rescatar el verdadero sentido de la política.

\section{Una complementariedad posible entre Benjamin y Arendt}

A partir de las consideraciones precedentes, exploraremos en este apartado una posible complementariedad entre las reflexiones de Benjamin y de Arendt sobre la violencia, el poder y la revolución. Más específicamente, lo que nos interesa es ver aquí qué ideas de estos autores pueden ser productivas para pensar el problema de la aparición de nuevos agentes políticos en el espacio público-político. Nuestra hipótesis es que la idea de una irrupción de nuevos actores políticos y la consecuente creación de nuevos espacios para la acción y el discurso, en el caso de Arendt, y la idea de "generaciones de vencidos", la cual remite a una tradición de los oprimidos, esto es, a experiencias políticas del pasado que han quedado ocultas, en el de Benjamin, redefinen el rol de la violencia y el poder, y por ende también de la revolución, en el espacio público-político. Finalmente concluiremos, en el siguiente apartado, con algunas reflexiones sobre la relevancia que estas redefiniciones podrían tener para pensar experiencias políticas concretas.

Como hemos visto en el apartado dedicado al pensamiento de Arendt sobre las cuestiones que nos interesan, el interés por las revoluciones modernas estriba, por un lado, en el poder de reunión y, por otro lado, en la fundación de un nuevo orden político. La fundación tiene sentido sólo en la medida en que otorga un marco de estabilidad y perdurabilidad a los nuevos espacios de libertad ganados por la irrupción de nuevos actores sociales en la escena política. Al mismo tiempo, la fundación implica un movimiento entre lo viejo y lo nuevo, es decir, entre las instituciones fundadas con anterioridad y los nuevos organismos, mediante la creación de leyes que no partan de un fundamento ontológico sino del consenso entre los individuos. Esto es así ya que el ámbito de la política es necesariamente contingente $y$, en este sentido, las instituciones revolucionarias deben apostar por este movimiento dialógico entre lo antiguo y lo nuevo. Además, una vez efectuada la fundación, la violencia debe diluirse en pos del poder de reunión. Esto porque, como señala Annabel Herzog ${ }^{34}$, para Arendt la diferencia entre ambas categorías se basa en la distinción entre "justificación" y "legitimidad": la violencia solo puede ser justificada, pues solo posee validez en tanto instrumento para la realización de objetivos futuros; el poder de reunión, en cambio, se relaciona con el acto de asociación que funda una comunidad política, por lo que obtiene su validez a partir de eventos que sucedieron en el pasado. En este sentido, para Arendt la tradición, nos recuerda Herzog, no es más que la sedimentación de capas de poder pasado. Desde nuestra perspectiva, aquí hay un importante punto de conexión con las reflexiones benjaminianas, las cuales apuntan también a una revalorización del pasado como legitimación de acciones en el presente. En efecto, para él, la acción política emancipadora en el presente se nutre "de la imagen

34 Cf. A. Herzog, op. cit. 


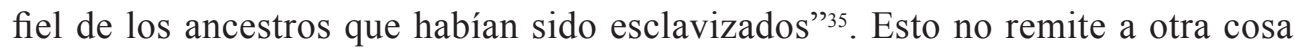
que a la "tradición de los oprimidos" ${ }^{36}$. Esta preocupación por el pasado, clara en ambos autores, nos parece un buen punto de partida para sugerir que la propuesta arendtiana sobre el poder de reunión y la dinámica de la fundación podría complementar la idea benjaminiana de una violencia que respondería a las "demandas sociales" de los vencidos de la historia.

En efecto, como veíamos en el apartado sobre la crítica de la violencia de Benjamin, su preocupación era plantear el problema de la posibilidad de una forma de acción política violenta que rompa con la violencia legal. Esta última, debido a que funciona de manera cíclica (la filosofía de la historia de la Gewalt) y a que anexa la vida a la culpa y a la retribución, constituye una realidad mítica. Para Benjamin no existe una diferencia entre la creencia mítica en la culpa y el destino y el principio moderno de la ley y el juicio. El destino como lo opuesto a la libertad se origina a partir de la esfera de lo mítico, ámbito donde el hombre se encuentra subordinado a la voluntad de los dioses. Es por esto que, en Benjamin, la oposición entre el paganismo mítico y lo divino monoteísta funciona como un dispositivo analítico para criticar al estado capitalista moderno y su violencia legal. Esta idea de la política como crítica del mito aparece en varios ensayos de la misma época, particularmente en Capitalismo como Religión, Las Afinidades electivas de Goethe y en Destino y Carácter. Desde esta perspectiva, para Benjamin no puede existir un orden ético basado en un "plexo de culpa de todo lo vivo" ${ }^{77}$, pues el nexo de culpa y retribución es una creencia mítica que no puede ser fusionada con el punto de vista ético-político de la justicia. En síntesis, para Benjamin el problema consiste en pensar la posibilidad de una violencia que no sea mítica y, por lo tanto, justa. De otra parte, En la conclusión de la introducción de Sobre la violencia, Arendt también recurre a la crítica del pensamiento mítico, pero para sostener que es este tipo de pensamiento el que liga la violencia con la creación de nuevos espacios de aparición de la acción y del discurso. Según Birmingham, sin embargo, esto no debe ser entendido como una contraposición a la propuesta benjaminiana de una violencia justa. Esta autora sostiene, en cambio, que la distinción arendtiana entre violencia instrumental, de un lado, y poder, del otro, está basada en la distinción que realiza benjamín entre violencia mítica y divina. Si bien esta tesis nos parece arriesgada, consideramos que podría apoyarse en un suelo más firme a condición de vincular la idea de poder de reunión con la idea de la posibilidad de una violencia justa basada en la acción política de los oprimidos de la historia, cuestión ausente en las consideraciones de Birmingham.

En términos más concretos, partimos aquí de la premisa de que el derecho moderno consiste fundamentalmente en un dispositivo cuyo objetivo es el de mantener la dominación política y la opresión social. En tal dirección, en las tesis Sobre el Concepto de Historia, Benjamin captura de manera significativa el problema de la existencia de una clase de personas dominada y oprimida. Aunque hay pasajes que sugieren que Benjamin se refiere a la clase obrera, hay otros que apuntan a la idea más amplia de "generaciones de vencidos" 38 , es decir, a los grupos sociales víctimas del

\footnotetext{
W. Benjamin, "Sobre el concepto de historia", op. cit., p. 314.

Ibidem, p. 309.

W. Benjamin, "Destino y carácter”, en Obras II/1, Madrid, Abada, 2007, pp. 175-182, aquí p. 179.

"El sujeto del conocimiento histórico es la misma clase oprimida que lucha. En Marx aparece como la última clase esclavizada, la vengadora, que lleva hasta el final la que es la obra de la liberación en nombre de generaciones de vencidos" (W. Benjamin, "Sobre el concepto de historia", op. cit., p. 313).
} 
poder presente, pero fundamentalmente del poder pasado. Sustantivamente, afirma Benjamin que la verdad de la historia se mide por su capacidad de generar imágenes de la injusticia pasada, las que, a su vez, pueden llegar a producir una fuerza social y política capaz de destruir el destino violento que asigna a los individuos a una clase ${ }^{39}$ que, insistimos en este punto, no se reduce a una categoría socioeconómica, sino que hace referencia a las víctimas de la dominación y la opresión ${ }^{40}$. La justicia, en este marco, está vinculada a la deposición de una ley que estructura el orden al asignar roles de clase a las personas, que estructura la sociedad en dominadores y dominados, opresores y oprimidos. De esta manera es posible pensar en un tipo de violencia concreta que rompa con el continuum del derecho. Esta violencia, para ser justa, solo puede ser la praxis misma de los oprimidos. En este sentido, Benjamin sostiene que "la justicia es el lado ético de la lucha" ${ }^{41}$. Lo que queremos sugerir, en definitiva, es que esta idea de "generaciones de vencidos" permite pensar en la práctica un tipo de violencia política justa y superar la afirmación de Arendt de que la violencia es siempre pre-política, basada en una concepción restringida de la política y su relación con lo que ella denomina "cuestión social", lo cual no le permite distinguir entre dominadores y dominados, opresores y oprimidos.

\section{Consideraciones finales sobre el poder, la violencia y la revolución}

A lo largo de este trabajo hemos intentado mostrar los planteos de Benjamin y de Arendt sobre la violencia, el poder y la revolución. En particular, quisimos ensayar una posible complementación entre las concepciones de ambos autores, pues considerábamos que esta operación nos permitiría esclarecer algunas problemáticas que se nos presentaron a la hora de pensar la política concreta a través de las categorías que nos proponen. Nos referimos, específicamente, a casos de aparición de nuevos agentes políticos en el espacio público-político, como el fenómeno del "Ni Una Menos" argentino ${ }^{42}$. Esta irrupción masiva, en algunos casos violenta, de las mujeres

39 M. Tomba, op. cit., p. 141.

40 "La naturaleza de dicha tristeza se nos hace más clara si se plantea la pregunta de con quién empatiza, propiamente hablando, el historiógrafo del historicismo. La respuesta suena, indefectible: empatiza con el vencedor. Pero los cada vez poderosos son los herederos de los que siempre han vencido. La empatía con los vencedores siempre beneficia por consiguiente a los cada vez poderosos [...] Quien quiera que, por tanto, hasta este día haya conseguido la victoria marcha en el cortejo triunfal en que los que hoy son poderosos pasan por encima de esos otros que hoy yacen en el suelo [...] No hay documento de cultura que no lo sea al tiempo de barbarie. Y como el mismo no está libre de barbarie, tampoco lo está el proceso de transmisión en el cual ha pasado desde el uno al otro. Por e so el materialista histórico se distancia de ella en la medida en que es posible hacerlo. Y considera como su tarea cepillar la historia a contrapelo" (W. Benjamin, "Sobre el concepto de historia", op. cit., p. 309).

${ }_{41}$ W. Benjamin, "Notes to a Study on the Category of Justice", en E. Jacobson, Metaphysics of the Profane. The Political Theology of Walter Benjamin and Gershom Scholem, New York, Columbia University Press, 2015, pp. 165-168, aquí pp. 167-168.

42 Según La Casa del Encuentro, una organización feminista independiente que se encarga de realizar estadísticas sobre la situación de las mujeres en Argentina, entre 2008 y 2014 se cometieron 1808 femicidios en el país. En 2015, el año había iniciado con casos de femicidios que habían conmocionado a la opinión pública. Uno en particular, el de Chiara Paéz, fue el disparador de la convocatoria de lo que paso a conocerse como el "Ni Una Menos", una movilización que fue definida como "un grito colectivo contra la violencia machista", especialmente contra los femicidios. Convocada por activistas, periodistas y artistas, el 3 de junio se realizó la multitudinaria marcha en la Plaza del Congreso y en todas las plazas centrales del interior del país, de las más masivas que se hayan visto en la historia reciente, que no sólo llamó la atención sobre los femicidios, sino que también impuso la agenda de las mujeres en el escenario político nacional y abrió el debate en amplias capas de la población. 
en el espacio público-político en tanto grupo social dominado y oprimido, y la posterior fundación de espacios estables para la acción y el discurso, nos mostraba las insuficiencias de las propuestas de Arendt y de Benjamin, cada una por su lado, para reflexionar sobre estos procesos. Por este motivo, consideramos que la combinación de ciertos planteos centrales de ambos autores operan una redefinición de las categorías de violencia, poder y revolución, permitiendo una articulación novedosa que habilita una nueva lectura de procesos de aparición de nuevos sujetos políticos en el espacio público.

En efecto, Benjamin entiende a la violencia en conexión con el derecho y la justicia. En el primer caso, la violencia-derecho posee características míticas, por lo que niega la libertad de los seres humanos. En el segundo, la violencia-justicia rompe con el continuum del derecho y libera a los seres humanos. En Arendt, en cambio, la violencia solo adquiere un sentido político en las revoluciones modernas, subordinada al "poder de reunión", es decir, siempre y cuando establezca espacios de libertad en los que la violencia ya no tenga lugar. Sin embargo, debido a su concepción restringida de la "cuestión social", Arendt no parece distinguir entre dominadores y dominados, opresores y oprimidos, por lo que no puede explicar por qué las revoluciones políticas contemporáneas han fracasado en establecer espacios de libertad. En este sentido, la idea de "parcialidad de clase" de Benjamin puede servir como correctivo. En efecto, solo las "generaciones de vencidos", al oponerse a la dominación y a la opresión de la que son víctimas, pueden ejercer una violencia justa y generar estos espacios de libertad a los que hace referencia Arendt. O, en términos arendtianos, solo las "generaciones de vencidos" pueden ejercer una violencia subordinada al "poder de reunión", esto es, libre de la lógica instrumental.

Por otro lado, dado que Benjamin piensa la violencia revolucionaria en términos "anarquistas" (o, más exactamente, a través de los lentes del marxismo sindicalista soleriano), es decir, de manera negativa y destructiva, o, en otras palabras, como liberación, no puede pensar la constitución un nuevo cuerpo político que otorgue estabilidad a la innovación y al discurso, esto es, a la libertad. Aquí es donde pensamos que la contribución de Arendt puede ser significativa. En efecto, en Sobre la revolución, la autora replantea la relación entre violencia y acción tomando distancia de "la tradición mítica"43 en la que han caído pensadores como Thomas Hobbes o Carl Schmitt. Pues mientras que estos sostienen que la ley lleva ínsita una violencia cuyo fin es mandar y obedecer, la ley en Arendt está enraizada en alianzas y tratados entre diferentes esferas del poder. La ley, en este sentido, no es instrumental, no necesita ser justificada, sino que al hundir sus raíces en el poder, necesita ser legitimada. Esto permite el diálogo entre el pasado y el presente dejando abierta la posibilidad a nuevos estallidos revolucionarios, una vez que la ley se haya deslegitimado. En este sentido, la desobediencia civil está justificada y en ningún caso puede ser equiparada a la desobediencia delictiva:

La distinción entre una abierta violación de la ley ejercida en público y una clandestina es tan obvia que sólo puede ser ignorada por prejuicio o mala fe. [...] El

Desde entonces, la fecha se ha incorporado al calendario feminista. A la vez, numerosos espacios para la acción y el discurso de las mujeres han emergido como consecuencia de la convocatoria inicial, mientras que otros ya existentes, como el Encuentro Nacional de Mujeres, aumentaron su convocatoria exponencialmente (en el encuentro del año 2017, se calcula que en los "talleres" participaron más de 70 mil mujeres de todo el país).

43 Cf. P. Birmingham, op cit. 
transgresor común, aunque pertenezca a una organización delictiva, actúa en su propio beneficio; se niega a ser cooptado por el consentimiento de los demás y se someterá únicamente a la violencia de las organizaciones encargadas de hacer cumplir la ley. El desobediente civil, actúa en nombre y a favor de un grupo; desafía a la ley y a las autoridades con el fundamento de un disenso básico y no porque quiere obtener en tanto individuo una excepción para su propio beneficio ${ }^{44}$.

En la desobediencia civil se manifiesta de manera pura el disenso de un grupo que ya no se siente representado ni amparado por la ley. Es el poder del grupo el que lleva adelante una manifestación pública, movidos por el mismo espíritu de la ley. En este sentido, la definición arendtiana de fundación permitiría soslayar el problema benjaminiano de la creación de un espacio político liberado del mito, donde son posibles nuevas irrupciones revolucionarias dado el carácter dialectico entre lo viejo, esto es, lo que permanece y da estabilidad a un espacio político, y lo nuevo, es decir, el acontecimiento mismo de la revolución. Pues en palabras de Arendt:

Dado que, en toda revolución, el acontecimiento más importante es el acto de fundación, el espíritu revolucionario contiene dos elementos que nos parecen irreconciliables e incluso contradictorios. De un lado, el acto de fundar un nuevo cuerpo político, de proyectar la nueva forma de gobierno, conlleva una profunda preocupación por la estabilidad y durabilidad de la nueva estructura; la experiencia, por otro lado, con que deben contar quienes se comprometen en estos graves asuntos consiste en sentirse estimulados por la capacidad humana para todo origen, en poseer el elevado espíritu que siempre ha acompañado el nacimiento de algo nuevo sobre la tierra ${ }^{45}$.

44 H. Arendt, Crisis de la república, op. cit, p. 82.

45 H. Arendt, Sobre la revolución, Bs As, Siglo XXI, 1992, p. 230. 